\title{
IGF-1 protects against angiotensin II-induced cardiac fibrosis by targeting aSMA
}

\author{
Sangmi Ock ${ }^{1}$, Woojin Ham ${ }^{1}$, Chae Won Kang ${ }^{1}$, Hyun Kang ${ }^{2}$, Wang Soo Lee ${ }^{3 凶}$ and Jaetaek Kim ${ }^{1 凶}$ \\ (c) The Author(s) 2021
}

The insulin-like growth factor 1 receptor (IGF-1R) signaling in cardiomyocytes is implicated in physiological hypertrophy and myocardial aging. Although fibroblasts account for a small amount of the heart, they are activated when the heart is damaged to promote cardiac remodeling. However, the role of IGF-1R signaling in cardiac fibroblasts is still unknown. In this study, we investigated the roles of IGF-1 signaling during agonist-induced cardiac fibrosis and evaluated the molecular mechanisms in cultured cardiac fibroblasts. Using an experimental model of cardiac fibrosis with angiotensin II/phenylephrine (Angll/PE) infusion, we found severe interstitial fibrosis in the Angll/PE infused myofibroblast-specific IGF-1R knockout mice compared to the wild-type mice. In contrast, low-dose IGF-1 infusion markedly attenuated Angll-induced cardiac fibrosis by inhibiting fibroblast proliferation and differentiation. Mechanistically, we demonstrated that IGF-1-attenuated Angll-induced cardiac fibrosis through the Akt pathway and through suppression of rho-associated coiled-coil containing kinases (ROCK)2-mediated a-smooth muscle actin (aSMA) expression. Our study highlights a novel function of the IGF-1/IGF-1R signaling in agonist-induced cardiac fibrosis. We propose that low-dose IGF-1 may be an efficacious therapeutic avenue against cardiac fibrosis.

Cell Death and Disease (2021)12:688; https://doi.org/10.1038/s41419-021-03965-5

\section{INTRODUCTION}

Cardiac fibrosis characterized by excessive synthesis or diminished degradation of extracellular matrix (ECM) proteins is a hallmark of nearly all types of heart disease and contributes to the progression of heart failure [1]. Upon mechanical or biochemical stimulation, resident cardiac fibroblasts become activated and differentiate into a-smooth muscle actin (aSMA)-expressing myofibroblasts, which are critical in the exacerbated secretion of ECM $[2,3]$. Multiple signaling pathways have been implicated in the conversion of fibroblasts into myofibroblasts including transforming growth factor $\beta$ (TGF $\beta$ )/mothers against decapentaplegic homolog (Smad), angiotensin II (Angll), endothelin, and winglessrelated integration site $(\mathrm{Wnt}) / \beta$-catenin [1]. Although both angiotensin-converting enzyme inhibitors (ACEls) and Angll receptor blockers (ARBs) have already shown significant efficacy in reducing cardiac fibrosis in human and animal models of heart failure, they have not been approved for the treatment of cardiac fibrosis [4]. In this context, suppression of myofibroblast differentiation could be an effective therapeutic approach to prevent excessive cardiac fibrosis.

Insulin-like growth factor (IGF)-1 is mainly synthesized by the liver which binds its ubiquitously expressed cognate receptor, IGF1 receptor (IGF-1R). Studies of cardiomyocyte-specific knockout (KO) or transgenic IGF-1R mice showed that IGF-1R activates phosphoinositide 3-kinase (PI3K)-Akt signaling pathways through its intrinsic tyrosine kinase activity and regulates cardiomyocyte survival, hypertrophy, and aging [5-7]. In addition, some pieces of evidence are suggesting that IGF-1 signaling has beneficial effects against cardiac fibrosis. Cardiac overexpression of IGF-1R prevents diabetes-induced cardiac fibrosis and diastolic dysfunction [8]. Furthermore, the microencapsulated IGF-1 therapy reduces cardiac fibrosis in the porcine acute myocardial infarction model [9]. However, the role of IGF-1/IGF-1R signaling in the development of myocardial interstitial fibrosis under non-ischemic cardiac injury has never been directly addressed.

The present study was undertaken to examine the hypothesis that (1) deletion of IGF-1R in cardiac myofibroblasts causes aggravation of cardiac fibrosis against agonist-induced cardiac injury, and that (2) Angll-induced cardiac fibrosis could be alleviated by IGF-1 administration. Further, we determined underlying mechanisms of the inhibitory effect of IGF-1 in Angllinduced cardiac fibroblast differentiation.

\section{RESULTS \\ IGF-1R expression patterns in mouse hearts and generation of CFIGF1RKO mice}

Firstly, we examined the levels of IGF-1R in cardiac fibroblasts compared with cardiomyocytes isolated from mouse hearts using Langendorff perfusion. Surprisingly, semi-quantitative RT-PCR analysis revealed higher expression of IGF-1R mRNA in cardiac fibroblasts than in cardiomyocytes (Fig. 1A). To assess the effects of fibrotic agonists on IGF-1/IGF-1R expression in cardiac cells, we infused C57BL6 mice with Angll and phenylephrine (Angll/PE)

\footnotetext{
${ }^{1}$ Division of Endocrinology and Metabolism, Department of Internal Medicine, College of Medicine, Chung-Ang University, Seoul, Korea. ${ }^{2}$ Department of Anesthesiology, College of Medicine, Chung-Ang University, Seoul, Korea. ${ }^{3}$ Division of Cardiology, Department of Internal Medicine, College of Medicine, Chung-Ang University, Seoul, Korea. 㔫email: wslee1227@cau.ac.kr; jtkim@cau.ac.kr Edited by S. Lavandero
}

Received: 14 February 2021 Revised: 16 June 2021 Accepted: 17 June 2021

Published online: 09 July 2021 
A

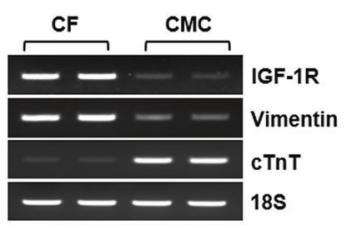

E
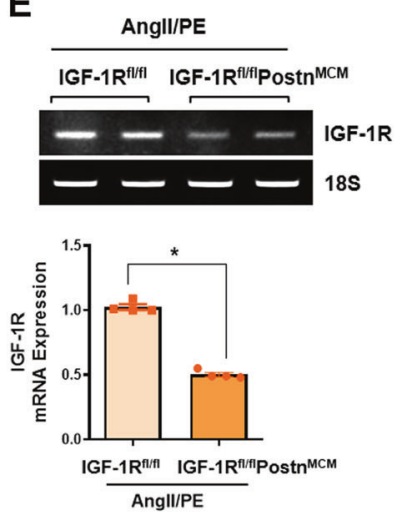

B

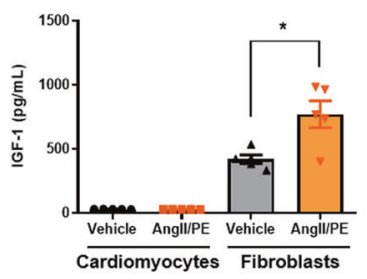

C

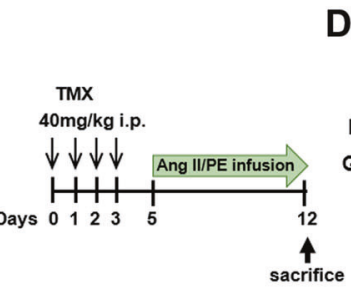

D

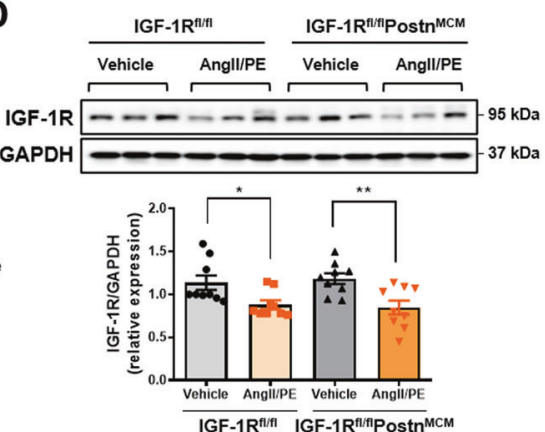

F

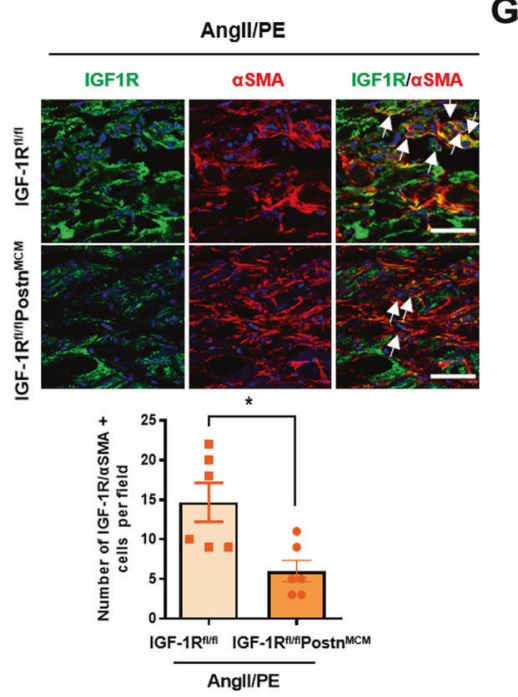

G

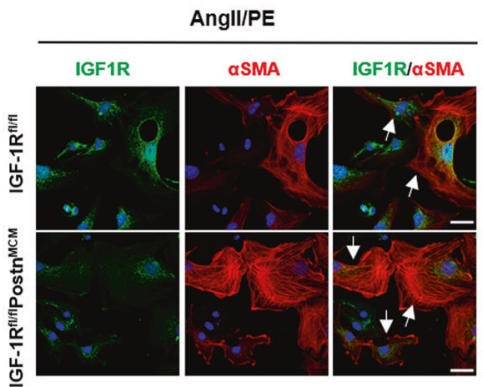

Fig. 1 Inducible myofibroblast-specific deletion of IGF-1R in mouse heart. A Semiquantitative RT-PCR analysis of $I g f-1 r$ mRNA expression in C57BL6 mouse cardiac fibroblasts and cardiomyocytes, characterized by vimentin and cardiac troponin T (cTnT), respectively. B Cardiomyocytes and fibroblasts were isolated from Angll/PE-infused C57BL6 WT hearts and cultured for 72 h. IGF concentrations in culture media were measured by ELISA. $n=5$ /group. C Schematic diagram of the experimental procedure. WT (IGF-1R ${ }^{\text {fl/fl }}$ ) or CFIGF1RKO (IGF$1 \mathrm{R}^{\mathrm{f} / \mathrm{f} / \mathrm{Postn}}{ }^{\mathrm{MCM}}$ ) mice were administered tamoxifen intraperitoneally for four consecutive days. From day 5 , the vehicle or Angll/PE mixture was infused by an osmotic minipump for 7 days, and the hearts were harvested. D Western blot analysis (upper panel) and densitometric ratios (lower panel) of IGF-1R. Group sizes: WT vehicle $(n=9)$, WT Angll/PE $(n=9)$, CFIGF1RKO vehicle $(n=9)$, CFIGF1RKO Angll/PE $(n=9)$. E Expression of Igf-1r mRNA in differentiated cardiac fibroblasts from Angll/PE-infused WT or CFIGF1RKO hearts. Representative RT-PCR is shown (upper panel). Relative levels of mRNA expression were normalized with respect to the levels of 18S and the mRNA level of WT hearts was arbitrarily set as 1. $n=4$ /group. F Double immunostaining of myocardial cryosections of Angll/PE-infused WT and CFIGF1RKO mice with anti-IGF-1R (green) and anti- $\alpha$ SMA (red) antibodies (upper panel) and quantification (lower panel). Nuclei were stained with DAPI (blue). Merged images are shown (magnification, $\times 40$, scale bar, $50 \mu \mathrm{m}$ ). To quantify IGF-1R/ $\alpha$ SMA-positive cells (arrows), a number of $\alpha$ SMA-expressing cells were counted based on the cells expressing IGF-1R. Group sizes: WT Angll/PE $(n=6)$, CFIGF1RKO Angll/PE ( $n=6)$. G Representative immunostaining for IGF-1R (green), $\alpha$ SMA (red) in isolated cardiac myofibroblasts from Angll/PE-infused WT and CFIGF1RKO mice. Arrows indicate stains of IGF-1R/ $\alpha$ SMA. Nuclei were stained with DAPI (blue). Merged images are shown (magnification, $\times 40$, scale bar, $25 \mu \mathrm{m}$ ). Data are presented as the mean \pm SEM. ${ }^{*} P<0.05 ;{ }^{* *} P<0.01$.

through osmotic minipumps for 7 days and then isolated and plated cardiomyocytes and cardiac fibroblasts. IGF-1 secretion was significantly increased in fibroblasts isolated from Angll/PE-infused mice compared with those isolated from vehicle-infused mice (Fig. 1B). By contrast, cardiomyocytes isolated from vehicle-infused or Angll/PE-infused mice secreted relatively low concentrations of IGF-1, suggesting that myofibroblast-derived IGF-1 may be involved in agonist-induced cardiac fibrosis.

Next, we sought to characterize the role of IGF-1R in the development of cardiac fibrosis. For this purpose, male CFIGF1RKO mice (8-10 weeks of age) were administered tamoxifen to mark activated fibroblasts followed by a 7-day infusion with fibrotic agonists Angll/PE and then harvested (Fig. 1C). Angll/PE significantly suppressed IGF-1R expression in the heart, suggesting that IGF-1/IGF-1R signaling may be protective against cardiac injury (Fig. 1D). Although IGF-1R expression was decreased in both Angll/PE-infused wild-type (WT) and CFIGF1RKO hearts, a 51\% lower lgf-1r mRNA expression was noted in activated cardiac fibroblasts and myofibroblasts from Angll/PE-infused CFIGF1RKO mice than in those from Angll/PE-infused WT mice (Fig. 1E). Furthermore, IGF-1R immunoreactivity was significantly decreased in myofibroblasts, as indicated by co-immunofluorescence for aSMA in myocardial cryosections (Fig. 1F) and isolated myofibroblasts (Fig. 1G), confirming the myofibroblast-specific ablation of IGF-1R.

\section{Genetic ablation of IGF-1R in myofibroblasts accelerates cardiac fibrosis in response to Ang II/PE infusion}

Angll/PE infusion for 7 days did not alter body weight (BW) but significantly increased heart weight, heart weight (HW) to BW ratios, and HW to tibia length (TL) ratios in both genotypes (Fig. 2A, B; Supplementary material online, Fig. S1A and S1B). In addition, both WT and CFIGF1RKO mice showed preserved cardiac contractile function as demonstrated by comparable fractional shortening after Angll/PE infusion (Fig. 2C; Supplementary material online, Table S1). These findings suggest that deletion 
A

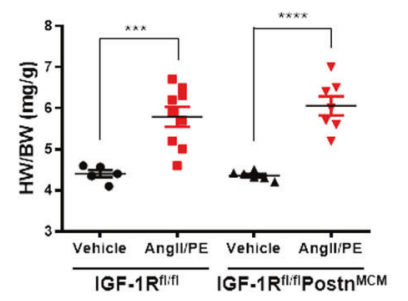

E

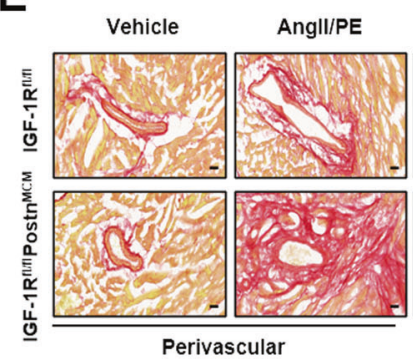

$\mathrm{H}$

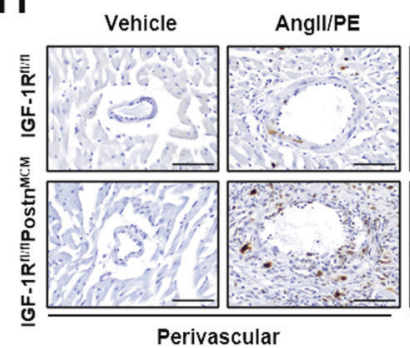

B
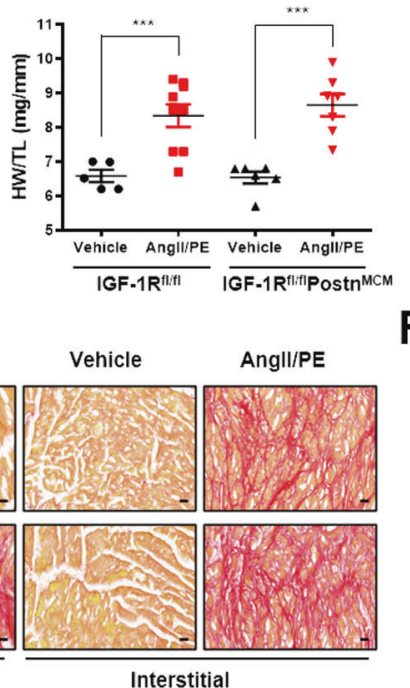

Interstitial

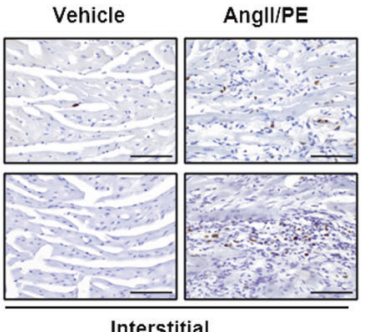

C

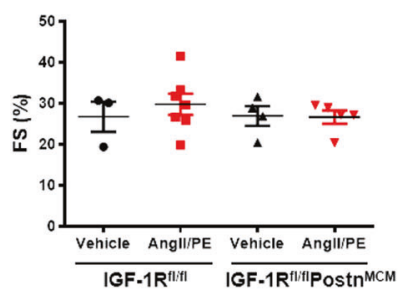

F

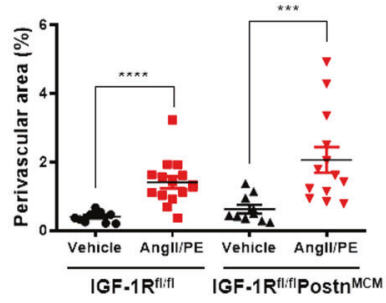

I

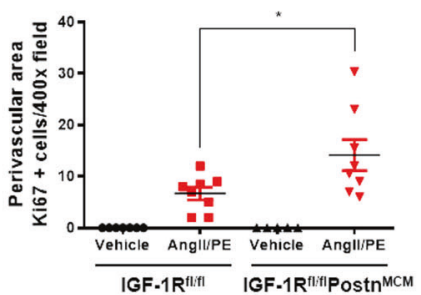

D

J

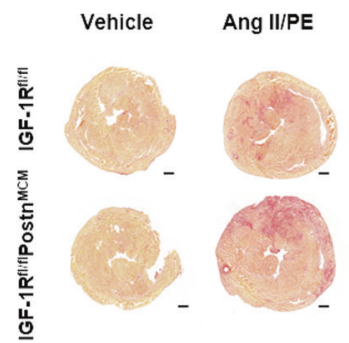

G
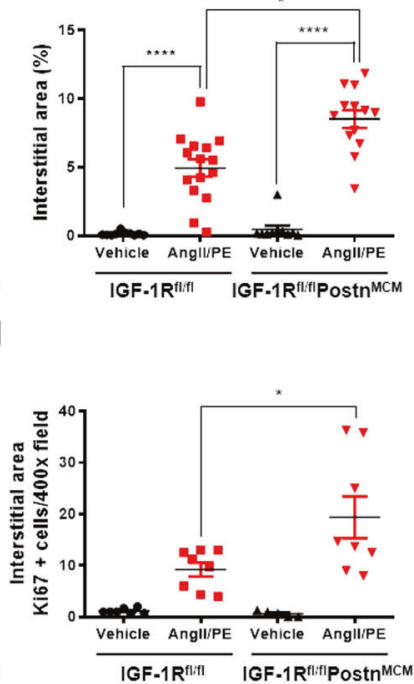

Fig. 2 Genetic ablation of IGF-1R in myofibroblast aggravates Angll/PE-induced cardiac fibrosis. A Heart weight to body weight (HW/BW) ratio. B Heart weight to tibia length (HW/TL) ratio. Group sizes: WT vehicle $(n=5)$, WT Angll/PE $(n=9)$, CFIGF1RKO vehicle $(n=6)$, CFIGF1RKO Angll/PE $(n=7)$. C Echocardiographic analysis of fractional shortening (FS). Group sizes: WT vehicle $(n=3)$, WT Angll/PE $(n=7)$, CFIGF1RKO vehicle $(n=4)$, CFIGF1RKO Angll/PE $(n=5)$. (D) Representative Sirius red staining of heart cryosections from vehicle or Angll/PE-infused mice (magnification, $\times 1.7,500 \mu \mathrm{m}$ ). E Representative Sirius red staining of the perivascular and interstitial areas (magnification, $\times 40,20 \mu \mathrm{m}$ ). Quantification of perivascular fibrosis (F) and interstitial fibrosis (G). Group sizes: WT vehicle $(n=10)$, WT Angll/PE $(n=15)$, CFIGF1RKO vehicle $(n=10)$, CFIGF1RKO Angll/PE $(n=13)$. H Representative images of Ki67 immunostaining (magnification, $\times 40,100 \mu \mathrm{m})$. Quantification of Ki67positive perivascular cells (I) and interstitial cells (J). Group sizes: WT vehicle $(n=7)$, WT Angll/PE $(n=8)$, CFIGF1RKO vehicle $(n=5)$, CFIGF1RKO Angll/PE $(n=8)$. Data are presented as the mean \pm SEM. ${ }^{*} P<0.05 ;{ }^{* * *} P<0.001 ;{ }^{* * * * * *} P<0.0001$.

of IGF-1R in myofibroblasts did not affect the degree of cardiac hypertrophy or contractile function.

Next, the Sirius red staining was performed to detect cardiac fibrosis. Myocardial collagen deposition was higher in Angll/PE infused CFIGF1RKO mice than in Angll/PE-infused WT mice (Fig. 2D). Mice subjected to Angll/PE infusion had higher perivascular and interstitial fibrosis than vehicle-infused mice (Fig. 2E-G). Interstitial fibrosis but not perivascular fibrosis was significantly higher in Angll/PE-infused CFIGF1RKO hearts than in Angll/PEinfused WT hearts. During activation, fibroblasts rapidly proliferate and upregulate cell cycle genes [3]. To detect proliferating cells, the sections were immunostained for Ki67, a marker of the cell cycle. Angll/PE-infused CFIGF1RKO hearts showed a dramatic increase in Ki67-positive cells in both perivascular and interstitial areas relative to Angll/PE-infused WT mice hearts (Fig. 2H-J). Ki67positive cells were primarily myofibroblasts (Supplementary material online, Fig. $\mathrm{S} 3 \mathrm{~A}-3 \mathrm{C}$ ). Furthermore, as illustrated in Fig. 3A, B, aSMA, expressions of myofibroblasts differentiation marker, was significantly higher in the perivascular area in Angll/PEinfused CFIGF1RKO mice than in Angll/PE-infused WT mice. In addition, there was a significantly larger interstitial aSMA-positive area in Angll/PE-infused CFIGF1RKO than in Angll/PE-infused WT mice (Fig. 3C). Although Smad2 phosphorylation was upregulated in both genotypes, phospho-Smad3 and phospho-Erk levels were significantly increased in Angll/PE-infused CFIGF1RKO hearts compared with those in Angll/PE-infused WT hearts (Fig. 3D-I). Moreover, collagen I, collagen III, Tgf $\beta 1, \operatorname{Tgf} \beta 2$, and Tgf $\beta 3$ mRNA expression levels were significantly higher in Angll/PE-infused CFIGF1RKO hearts than in Angll/PE-infused WT hearts (Fig. 3J-N). Thus, we conclude that IGF-1R in myofibroblasts is essential for limiting cardiac fibrosis in agonists-infused mice.

\section{Low dose IGF-1 attenuates Ang II-induced cardiac fibrosis irrespective of cardiac hypertrophy}

To determine whether IGF-1 had potential therapeutic effects on cardiac fibrosis, continuous low dose IGF-1 ( $20 \mathrm{ng} / \mathrm{g} /$ day) was coinfused in Angll-administrated mice for 7 days (Fig. 4A). Administration of Angll decreased BW to the same extent in both the genotypes (Supplementary material online, Fig. S2A and 2B). In addition, HW/BW and HW/TL were comparable between mice treated with Angll/vehicle and with Angll/IGF-1 (Fig. 4B, C). Although Angll infusion induced a similar degree of cardiac hypertrophy, fractional shortening, which increased in mice treated with Angll/vehicle, was not increased in Angll/IGF-1infused mice compared with that in Angll/vehicle-infused mice (Fig. 4D; Supplementary material online, Table S2). Moreover, IGF-1 treatment markedly attenuated Angll-induced interstitial fibrosis (Fig. 4E-H). Notably, Ki67-positive cells colocalized to aSMApositive cells (Supplementary Material Online, Fig. S4A and S4B) suggesting that IGF-1 suppressed cardiac fibroblast proliferation in 
A

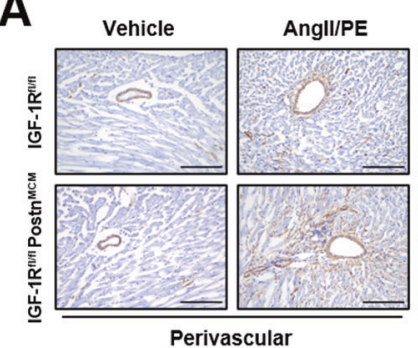

Vehicle

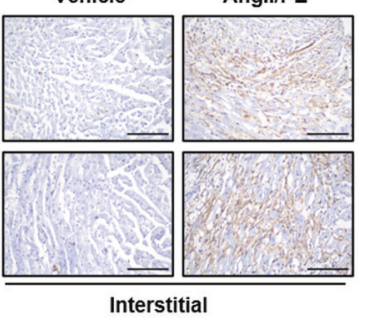

D

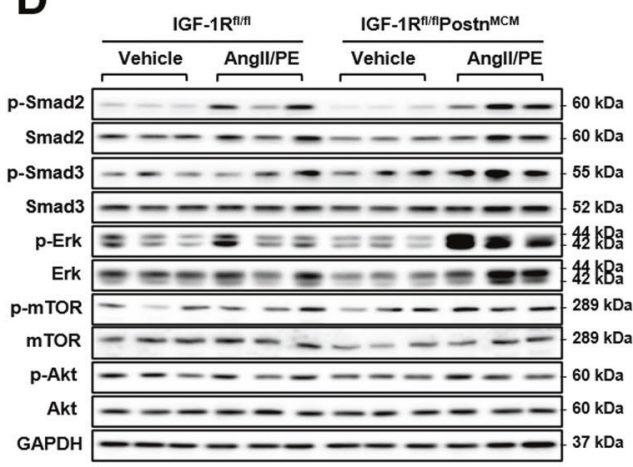

J

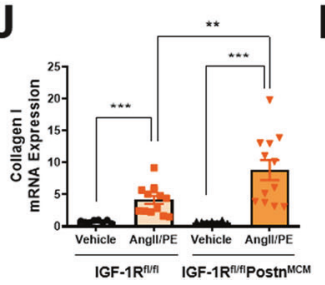

K

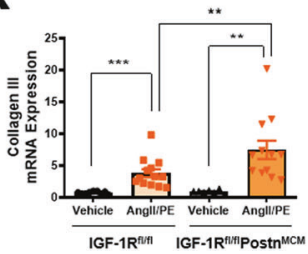

E

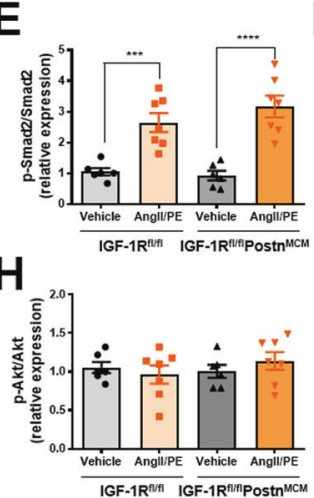

L

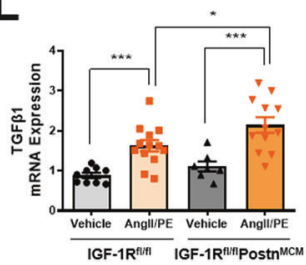

B

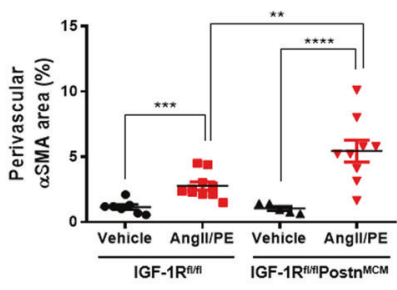

F

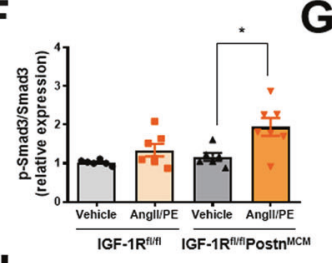

I

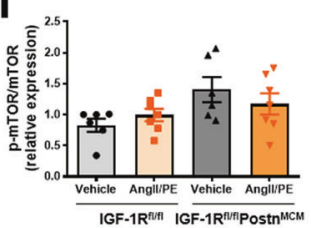

M

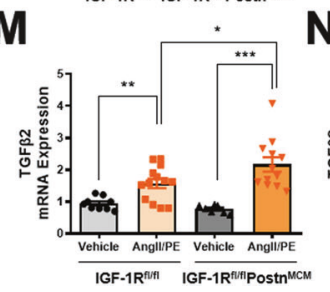

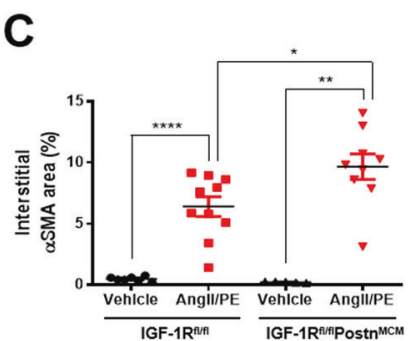

G

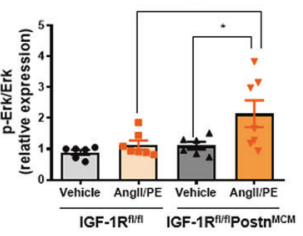

$\mathbf{N}$

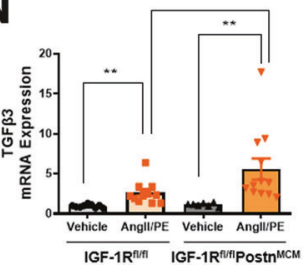

Fig. 3 Genetic ablation of IGF-1R in myofibroblast expands aSMA expression and promotes activation of Erk signaling in response to Angll/PE. A Representative images of $\alpha S M A$ immunostains (magnification, $\times 20,200 \mu \mathrm{m}$ ) at the perivascular and interstitial areas. Quantification of $\alpha$ SMA-positive perivascular (B) and interstitial (C) areas. Group sizes: WT vehicle $(n=7)$, WT Angll/PE ( $n=10)$, CFIGF1RKO vehicle $(n=5)$, CFIGF1RKO Angll/PE $(n=9)$. Western blot analysis (D) and densitometric ratios of phosphorylated Smad2 (E), phosphorylated Smad3 $(\mathbf{F})$, phosphorylated Erk $(\mathbf{G})$, phosphorylated Akt $(\mathbf{H})$, and phosphorylated mTOR (I). Group sizes: WT vehicle $(n=6)$, WT Angll/PE $(n=$ 6-7), CFIGF1RKO vehicle $(n=6)$, CFIGF1RKO Angll/PE $(n=6-7)$. mRNA quantification of collagen I (J), collagen III (K), Tgf $\beta 1$ (L), Tgf $\beta 2$ (M), and $\operatorname{Tgf} \beta 3$ (N). Results were normalized to $18 \mathrm{~S}$ and mRNA levels in the vehicle were arbitrarily set as 1 . Group sizes: WT vehicle $(n=9)$, WT Angll/PE $(n=13)$, CFIGF1RKO vehicle $(n=7)$, CFIGF1RKO Angll/PE $(n=12)$. Data are presented as the mean \pm SEM. ${ }^{*} P<0.05 ;{ }^{* * *} P<0.01 ;{ }^{* * *} P<0.001 ;{ }^{* * * *} P$ $<0.0001$.

Angll-administered mice (Fig. 4I-K). Furthermore, IGF-1 treatment suppressed Angll-induced myofibroblast differentiation, as indicated by decreased aSMA expression (Fig. 5A-D). In cardiac fibroblasts, rho-associated coiled-coil containing kinase (ROCK) 2 is necessary to cause cardiac hypertrophy and fibrosis [10]. Indeed, expression of ROCK2 but not ROCK1 was increased in Angllinfused hearts and was suppressed by IGF-1, supporting a crucial role of ROCK2 in the antifibrotic effects of IGF-1 (Fig. 5E, F). Moreover, IGF-1 significantly suppressed Angll-induced collagen and Tgf 33 mRNA expression (Fig. 5G-K). Infusion of Angll over 7 days increased systolic blood pressure, which was not affected by IGF-1 treatment, indicating that IGF-1 had blood pressureindependent antifibrotic effects (Supplementary material online, Fig. S5). These results show that IGF-1 treatment alleviates the progression of cardiac fibrosis in an established mouse model.

\section{Regulation of the inhibitory effects of IGF-1 on Angll-induced cardiac fibrosis by Akt-, and ROCK2-dependent signaling pathways}

IGF-1 inhibited myofibroblast differentiation, as demonstrated by decreased aSMA protein expression in Angll-treated adult rat cardiac fibroblasts (Fig. 6A, B). To explore the role of ROCK2, we stimulated cells with Angll for $0-24 \mathrm{~h}$. Notably, the expression levels of ROCK2 protein but not ROCK1 protein were time-dependently increased, accompanied by the upregulation of aSMA (Fig. 6C, D). To verify whether aSMA is a downstream target of ROCK2, we transfected ROCK2 siRNA into rat cardiac fibroblasts and treated them with Angll up to $24 \mathrm{~h}$. As shown in Fig. 6E-G, IGF-1 significantly suppressed Angllinduced upregulation of ROCK2 and ASMA as well. However, as a consequence of the knockdown of ROCK2, Angll-induced upregulation of aSMA was not observed, confirming that Angllregulated aSMA expression through ROCK2. These data suggested that ROCK 2 was a target of IGF-1 in Angll-induced cardiac fibroblast differentiation. In addition, treatment with ROCK2 siRNA inhibited Angll-induced phosphorylation of Smad2 and Smad3, indicating that ROCK2 was a critical target for regulating the fibrotic gene program (Fig. $6 \mathrm{H}-\mathrm{K}$ ). Although Angll phosphorylated both Smad2 and Smad3, treatment with IGF-1 inhibited phosphorylation of Smad3 but not Smad2. Moreover, the addition of the pharmacologic Smad3 inhibitor SIS3 blunted Angll-induced aSMA, suggesting that IGF-1 could directly or indirectly inhibit the activity of Smad3 which is located between Angll and aSMA (Fig. 6L-O). Finally, to determine whether IGF-1-Akt signaling regulated aSMA expression, we knocked down both Akt1 and Akt2 by transfection with Akt1 and Akt2 siRNA into cardiac fibroblasts. As shown in Fig. $6 \mathrm{P}-\mathrm{S}, \mathrm{Akt} 1$ and Akt2 knockdown represses the inhibitory effect 
A

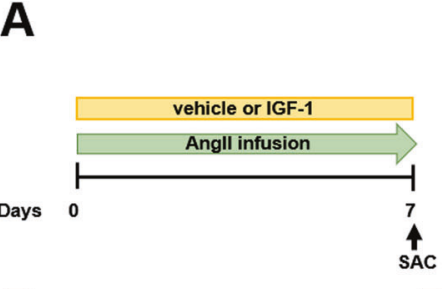

E

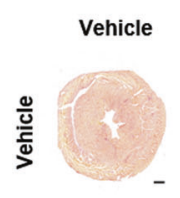

克
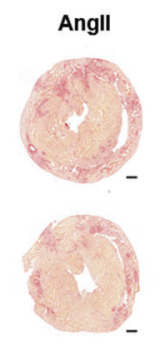

B

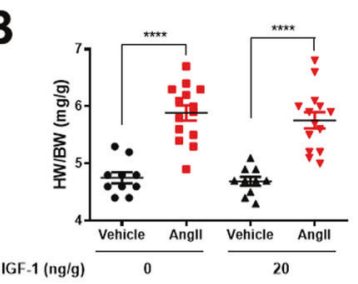

F
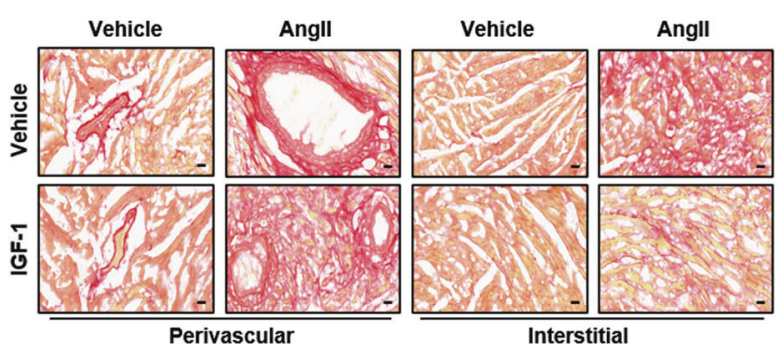

C

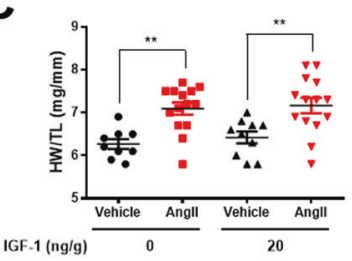

D

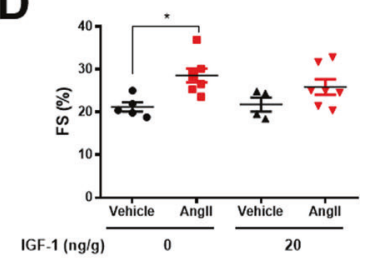

G
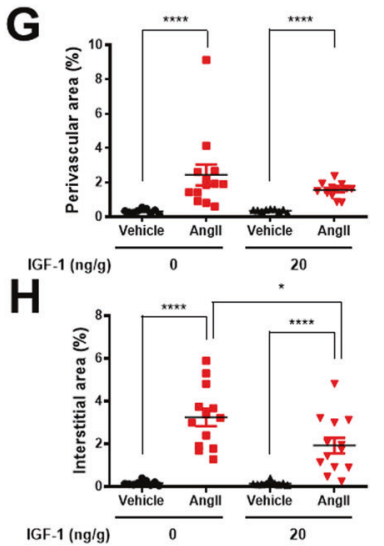

K

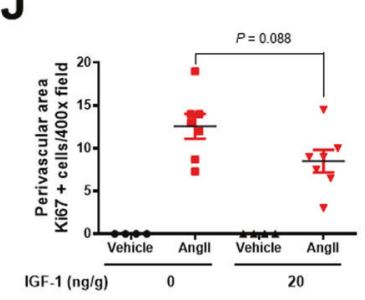

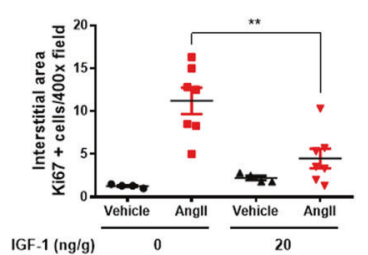

$\mathbf{J}$
I

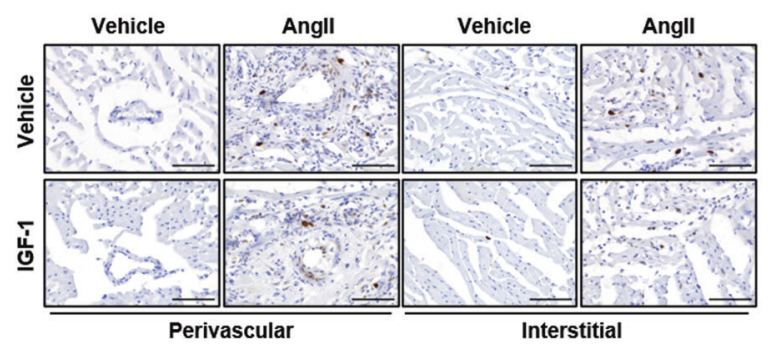

$$
\text { . }
$$

Fig. 4 Systemic infusion of low dose IGF-1 attenuates Angll-induced cardiac fibrosis. A Schematic diagram of the experimental procedure. IGF-1 (20 ng/g/day) or vehicle was co-infused with Angll (3 $\mathrm{gg} / \mathrm{g} /$ day) via a subcutaneously implanted osmotic minipump for 7 days in C57BL6 mice. B HW/BW ratio. Group sizes: vehicle $(n=10)$, Angll $(n=14)$, vehicle+IGF-1 $(n=10)$, Angll+IGF-1 $(n=14)$. C HW/TL ratio. Group sizes: vehicle ( $n=10)$, Angll $(n=14)$, vehicle+IGF-1 $(n=10)$, Angll+IGF-1 $(n=14)$. D Echocardiographic analysis of fractional shortening (FS). Group sizes: vehicle $(n=5)$, Angll $(n=7)$, vehicle+IGF-1 $(n=4)$, Angll+IGF-1 $(n=7)$. E Representative Sirius red staining of hearts from Angll-infused mice treated with or without IGF-1. F Representative Sirius red staining of the perivascular and interstitial areas (magnification, $x 40,20 \mu m$ ). Quantification of perivascular fibrosis (G) and interstitial fibrosis (H). Group sizes: vehicle $(n=9)$, Angll $(n=13)$, vehicle+IGF-1 $(n=9)$, Angll + IGF-1 $(n=13)$. I Representative images of Ki67 immunostaining (magnification, $\times 40,100 \mu$ m). Quantification of Ki67-positive perivascular cells $(\mathbf{J})$ and interstitial cells $(\mathbf{K})$. Group sizes: vehicle $(n=4)$, Angll $(n=7)$, vehicle+IGF-1 $(n=4)$, Angll+IGF-1 $(n=7)$. Data are presented as the mean \pm SEM. ${ }^{*} P<0.05 ;{ }^{* *} P<0.01{ }^{; * * * *} P<0.0001$.

of IGF-1 on Angll-induced aSMA expression. Based on the observation that phospho-Erk was increased in Angll/PE-infused CFIGF1RKO hearts, we also measured Erk phosphorylation. Phospho-Erk was significantly increased after Angll stimulation, whereas the addition of IGF-1 to Angll did not affect Erk phosphorylation, indicating that Erk signaling was not likely involved in mediating the Angll/aSMA pathway. Taken together, these results suggested that IGF-1 inhibited Angllinduced cardiac fibrosis through Akt-dependent and ROCK2associated pathways (Fig. 6T).

\section{DISCUSSION}

In the current study, we demonstrated a novel function of cardiac fibroblast IGF-1 signaling in the development of cardiac fibrosis. IGF-1 is mainly synthesized and secreted in the liver; however, some reports have shown that IGF-1 is also produced by cardiac fibroblasts upon exposure to pressure overload stimuli [5]. Here, we found that fibrotic agonists stimulated IGF-1 production from differentiated cardiac fibroblasts, which may be a compensatory response against cardiac injury. Moreover, via its cognate receptor IGF-1R in cardiomyocytes, fibroblast-derived IGF-1 may have essential roles in myocardial protection against pressure overload in mice [11].
Most studies on the role of cardiac IGF-1 signaling have focused on cardiomyocytes. Based on our previous reports, deletion of IGF$1 \mathrm{R}$ in cardiomyocytes contributes to abnormal cardiac remodeling, such as blunted hypertrophic response to exercise training [6] or delayed aging-associated myocardial pathologies [7]. However, to date, the roles of autocrine/paracrine IGF-1 signaling in cardiac fibroblasts against agonist-induced fibrosis remains elusive. In this study, we observed a higher expression of IGF-1R in cardiac fibroblasts than in cardiomyocytes. Moreover, decreased IGF-1R expression was observed in Angll/PE-infused hearts. This prompted us to investigate the protective role of cardiac fibroblast IGF-1R against injury-induced cardiac fibrosis. We showed that CFIGF1RKO hearts exhibited a more severe degree of fibrosis and myofibroblast differentiation than WT hearts in the Angll/PE infusion model. Thus, in fibroblasts, IGF-1R expression may counteract fibrosis against cardiac injury. Notably, CFIGF1RKO hearts exhibited higher Smad3 and Erk phosphorylation in response to Angll/PE stimuli. However, Smad2 phosphorylation, which is known to be increased by Angll treatment [12], was not significantly affected by IGF-1R deletion in myofibroblasts. Moreover, Akt was not involved in cardiac remodeling in our model. Thus, crosstalk between Smad3 and Erk signaling [13, 14] is likely to be involved in accentuated activation of fibrosis in Angll/PE- 
A
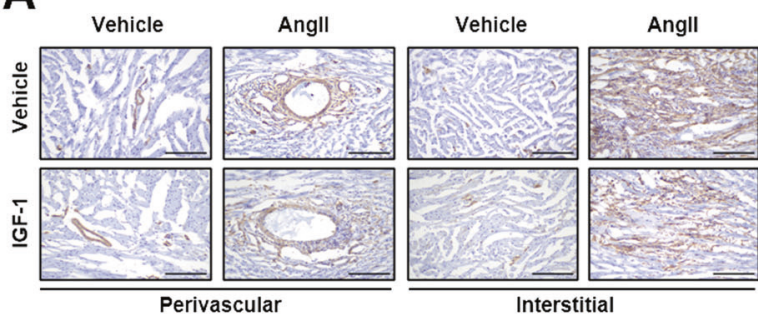

B

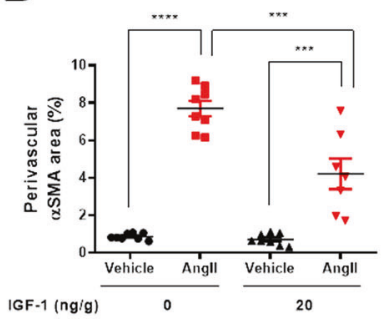

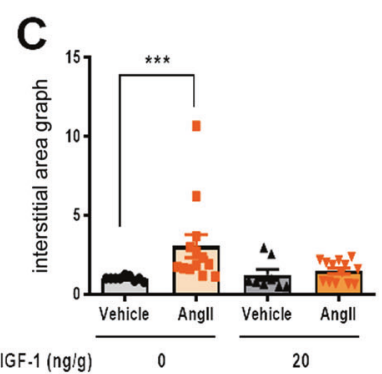
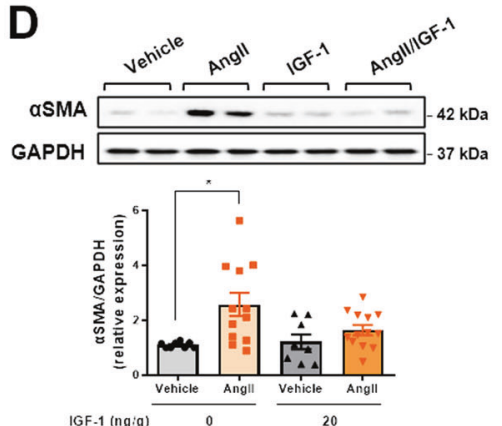

E
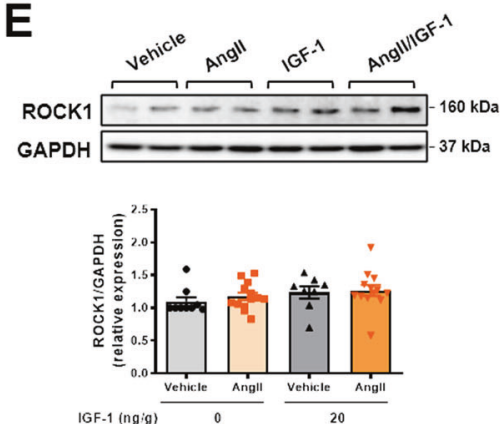

$\mathbf{F}$
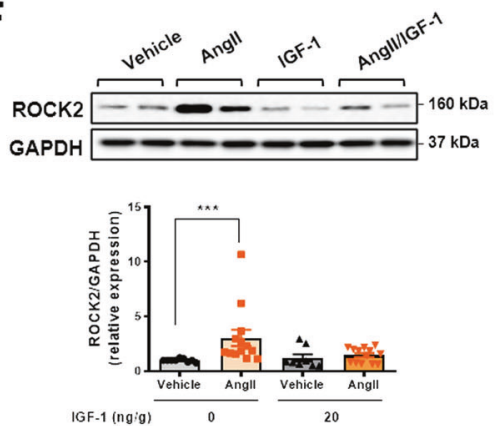

G

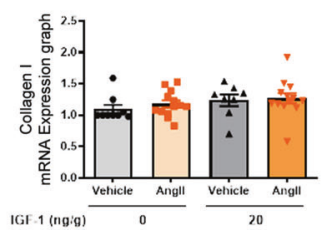

H

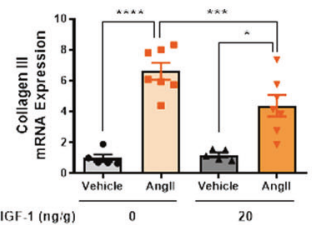

I

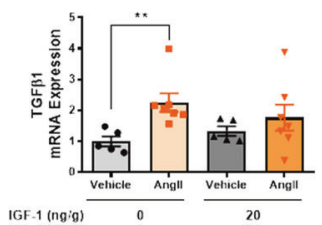

J

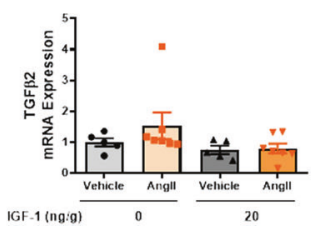

K

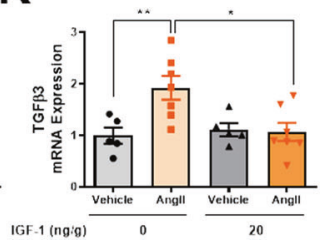

Fig. 5 Decreased myofibroblast differentiation and fibrosis-associated genes in IGF-1-treated fibrotic hearts. A Representative images of $\alpha S M A$ immunostaining (magnification, $\times 20,200 \mu \mathrm{m}$ ) at perivascular and interstitial area. Quantification of $\alpha$ SMA-positive perivascular (B) and interstitial (C) area. Group sizes: vehicle $(n=8)$, Angll $(n=8)$, vehicle+IGF-1 $(n=8)$, Angll+IGF-1 $(n=7)$. Western blot analysis and the densitometric ratio of $\alpha$ SMA (D), ROCK1 (E), and ROCK2 (F). Group sizes: vehicle $(n=8-9)$, Angll $(n=12-13)$, vehicle+IGF-1 $(n=8)$, Angll+IGF-1 $(n=13)$. mRNA quantification of collagen I (G), collagen III (H), Tgf $\beta 1(\mathbf{I}), \operatorname{Tgf} \beta 2(\mathbf{J})$, and Tgf $\beta 3$ (K). Results were normalized to $18 \mathrm{~S}$, and mRNA levels in vehicle were arbitrarily set as 1 . Group sizes: vehicle $(n=5)$, Angll $(n=7)$, vehicle+IGF-1 $(n=5)$, Angll+IGF-1 $(n=7)$. Data are presented as the mean \pm SEM. ${ }^{*} P<0.05 ;{ }^{* *} P<0.01 ;{ }^{* * *} P<0.001 ;{ }^{* * * *} P<0.0001$.

treated CFIGF1RKO mice. Taken together, these findings may account for injury-induced cardiac fibrosis that can be controlled by modifying the IGF-1/IGF-1R signaling.

Myocardial interstitial fibrosis is characterized by excessive accumulation of collagen in the ECM and it is a common finding of non-ischemic cardiomyopathy such as hypertensive heart disease [2]. Importantly, the degree of interstitial fibrosis is associated with cardiovascular death in patients with heart failure. A recent study has demonstrated that mitogen-activated protein kinase (MAPK) p38a deletion in myofibroblasts reduces the fibrotic response to ischemia injury [15]. Thus, it is prudent to explore strategies to inhibit fibroblast differentiation for the effective treatment of cardiac fibrosis. In terms of the phenotype conversion in critical evolution of cardiac fibrosis, cardiac fibroblasts proliferate and differentiate into secretory phenotype cells, e.g., myofibroblasts, which can be driven by many stimuli including mechanical force, TGF $\beta$, connective tissue growth factor (CTGF), and renin-angiotensin-aldosterone system (RAAS) activation. Angll is known to induce collagen synthesis through the AT1 receptor (AT1R)/TGF $\beta /$ Smads-signaling pathway in cardiac fibroblasts [16]. Clinical studies have shown that both ACEl lisinopril [17] and ARB losartan [18] reduce interstitial fibrosis in patients with hypertensive heart disease, independent of their anti-hypertensive effects. However, these drugs modestly regress cardiac fibrosis. Although clinical trials in patients with heart failure with preserved ejection fraction with pirfenidone, a TGF $\beta$ inhibitor approved for idiopathic pulmonary fibrosis, are ongoing [19], it remains to be established whether these drugs confer an additional anti-fibrotic benefit over ACEls or ARB [20]. Furthermore, Angll stimulates TGF $\beta$ production in cardiac fibroblasts and myofibroblasts and is required for Angllinduced cardiac hypertrophy and fibrosis [1, 21]. In addition, Angll can rapidly activate the Smad2/3 pathway independent of TGF $\beta$ activation during epithelial-mesenchymal transdifferentiation [22]. In the current study, we observed that IGF-1 treatment suppressed Angll-induced TGF $\beta 3$ expression, indicating that IGF-1 plays important role in suppressing Angll-induced TGF $\beta$ signaling. Thus, the involvement of the Angll/TGF $\beta / S M A D 2$ axis in the differentiation of fibroblasts into myofibroblasts may be much more complex and warrants further investigation.

IGF-1 has potential cardioprotective effects following cardiac injury through both pro-survival and anti-apoptotic mechanisms [23]. For example, low-dose $(600 \mathrm{pg})$ intracoronary IGF-1 administered following reperfusion in a porcine model of myocardial infarction was shown to have acute pro-survival effects on the myocardium [24]. In addition, one-time skeletal muscle injection of adeno-associated virus 5 encoding IGF- 1 in coronary occlusion heart failure rat model significantly reduced not only cardiomyocyte apoptosis but myocardial fibrosis [25]. However, the roles of IGF-1 in fibrosis are still controversial. Acromegalic patients exhibit myocardial hypertrophy and interstitial fibrosis depending on the duration of growth hormone and IGF-1 excess [26]. Recent studies have shown that short-term IGF- 1 treatment ( $1 \mu \mathrm{g} / \mathrm{g} /$ day) using an osmotic minipump for 3 days after acute myocardial infarction improves cardiac function by modulating the acute inflammatory 


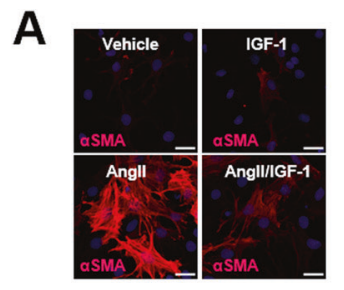

E

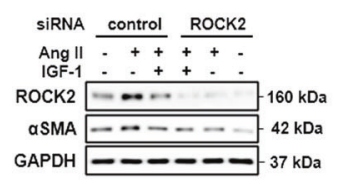

K

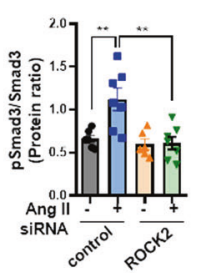

P

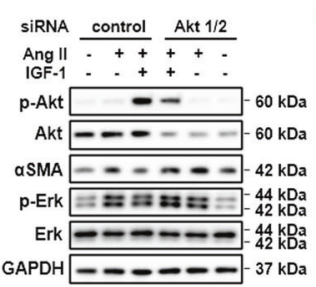

L
B

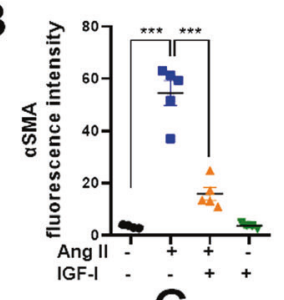

F
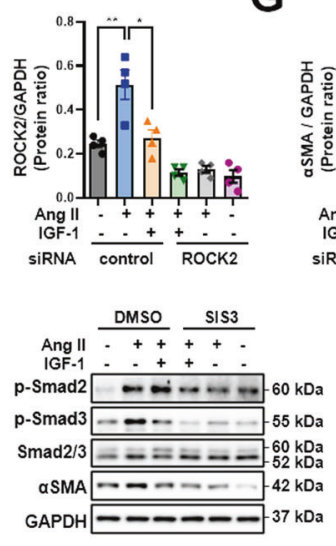

Q

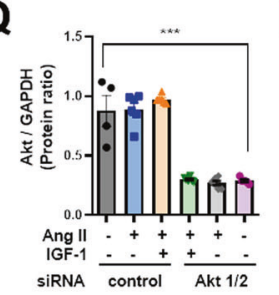

$\mathbf{R}$
C

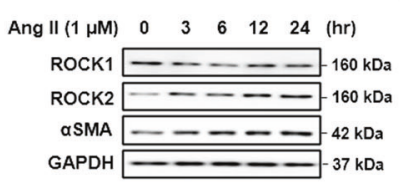

$\mathrm{H}$

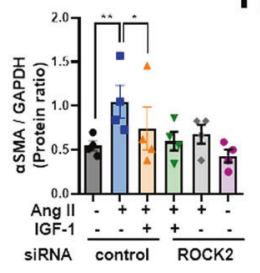

M

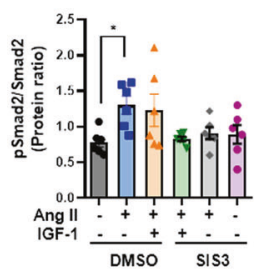

N
D

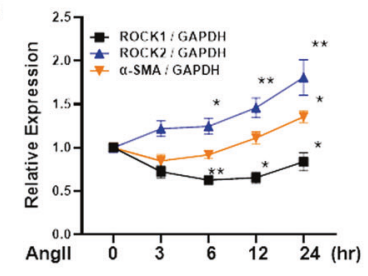

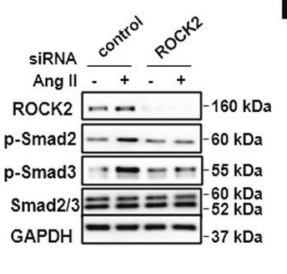
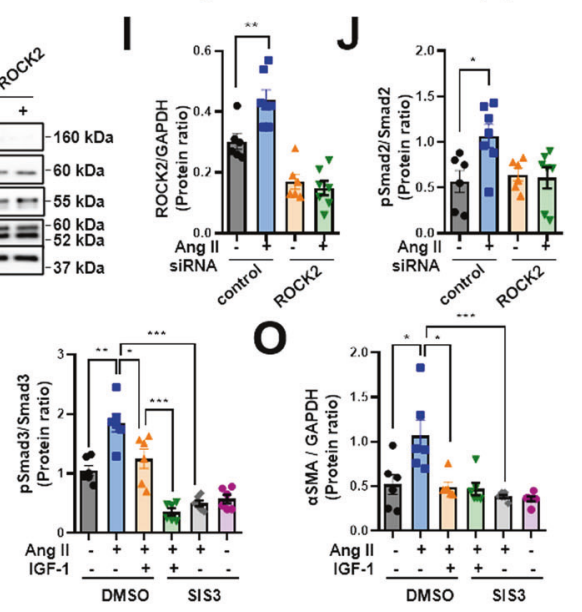

0
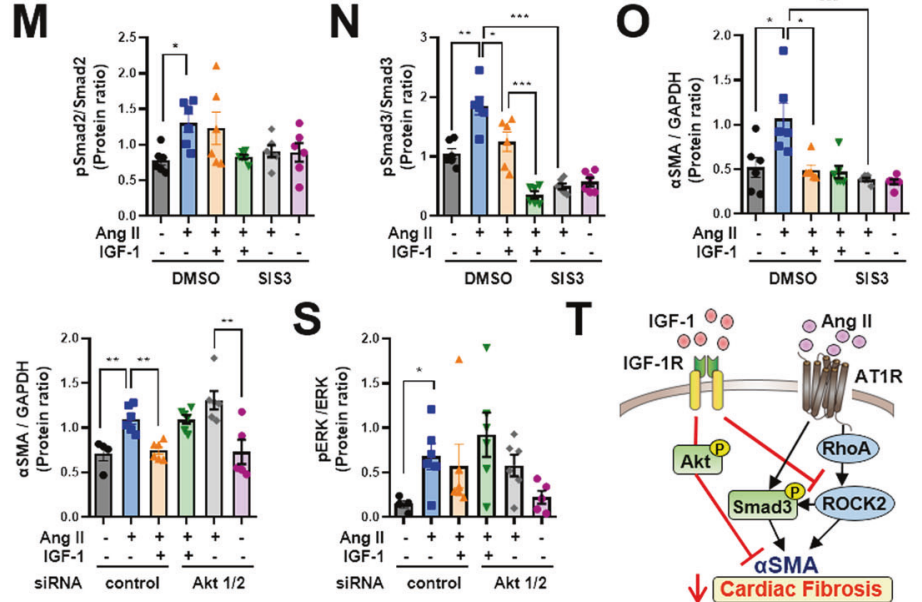

Fig. 6 Inhibitory effects of IGF-1 on Angll-induced differentiation of cardiac fibroblasts into myofibroblasts. A Adult rat cardiac fibroblasts were treated with Angll $(1 \mu \mathrm{M})$ or Angll plus IGF-1 $(100 \mathrm{ng} / \mathrm{mL})$ for $24 \mathrm{~h}$, and immunocytochemical staining was performed. Representative images of $\alpha$ SMA and DAPI (magnification, $\times 40,25 \mu \mathrm{m}$ ) and B quantification of fluorescence intensity. $n=4-7 / g r o u p$. Cells were treated with Angll for 3-24 $\mathrm{h}$. The lysates were then immunoblotted with the indicated antibodies. Western blot analysis (C) and densitometric ratios (D) of ROCK1, ROCK2, and $\alpha$ SMA. $n=4-6$. Cells were transfected with $30 \mathrm{nM}$ negative control or $30 \mathrm{nM}$ ROCK2 siRNA for $24 \mathrm{~h}$ and then incubated with vehicle or IGF-1 with Angll for $24 \mathrm{~h}$. Western blot analysis (E) and densitometric ratios (F, G). $n=4$ each. Knockdown of ROCK2 was performed in cardiac fibroblasts and treated with Angll for $6 \mathrm{~h}$. Western blot analysis $(\mathbf{H})$ and densitometric ratios $(\mathbf{I}, \mathbf{K})$. $n=6-7 / g$ roup. Cardiac fibroblasts were treated with vehicle or the Smad3 inhibitor SIS3 $(5 \mu \mathrm{M})$ for $40 \mathrm{~min}$ and then incubated with vehicle or IGF-1 with Angll for $24 \mathrm{~h}$. Western blot analysis (L) and densitometric ratios (M-O). $n=6$ /group. Cardiac fibroblasts were transfected with $10 \mathrm{nM}$ negative control or $5 \mathrm{nM}$ Akt1 and Akt2 siRNA for $24 \mathrm{~h}$ and then incubated with vehicle or IGF-1 with Angll for $24 \mathrm{~h}$. Western blot analysis (P) and densitometric ratios $(\mathbf{Q}-\mathbf{S}) . n=4-6 /$ group. Data are presented as the mean \pm SEM. ${ }^{*} P<0.05 ;{ }^{* * *} P<0.01{ }^{*}{ }^{* * *} P<0.001$. T Schematic diagram depicting the roles of IGF-1 signaling in modulating Angll-induced cardiac fibrosis.

phase but does not alleviate fibrosis [27]. We speculate that the beneficial effects of IGF-1 on cardiac fibrosis may vary depending on the treatment duration and dosing. Given that low-dose IGF-1 resulted in promising outcomes in the porcine study, we conducted a preclinical study with a nanomolar concentration of IGF-1. In addition, we provide a rationale to explain why continuous infusion may be an effective mode of drug delivery.

Although several studies examined the link between IGF-1 signaling and organ fibrosis, the precise mechanism is still obscure. IGF-1 induces senescence and limits fibrosis in a p53dependent manner in hepatic stellate cells [28]. IGF-1 protects against tubular fibrotic changes induced by renal injury via activation of the Erk pathway [29]. One novelty of the current study is the elucidation of the molecular basis for IGF-1 function during Angll stimulation. ROCK1 and ROCK2 are members of the serine/threonine-protein kinase family, which mediates the downstream effects of the small GTP-binding protein RhoA [30]. Excess activity of ROCKs can lead to the development of cardiovascular diseases. Recent studies have shown that the ROCK2 pathway in fibroblasts is critically important for mediating Angll-stimulated cardiac hypertrophy and fibrosis [10]. The nonselective ROCK inhibitor fasudil reduces the development of cardiac fibrosis in Angll-treated mice [31]. In the current study, Angll decreased the expression of ROCK1 in adult rat cardiac fibroblasts. Notably, cardiomyocyte-specific ROCK1 deficiency promotes pressure overload-induced cardiac hypertrophy and fibrosis, whereas cardiomyocyte-specific ROCK2-deficient mice show alleviation of cardiac hypertrophy and fibrosis under exposure to pressure overload, suggesting that inhibition of ROCK1 is not a suitable therapeutic strategy for heart failure [32]. Future studies using myofibroblast-specific ROCK1 KO mice may reveal the opposite roles of ROCK1 and ROCK2 in fibroblast differentiation. We demonstrated crosstalk between IGF-1 and Angll at ROCK2, suggesting that the IGF-1/ROCK2 cascade is responsible for protection from Angll-induced cardiac fibrosis. Previous studies have shown crosstalk between IGF-1R and AT1R via upregulation of their reciprocal receptors in response to IGF-1 or Angll stimulation in smooth muscle cells [33]. By contrast, our study demonstrated that IGF-1R signaling antagonized Angll signaling in cardiac fibroblasts. Additional studies are warranted to further 
elucidate the cross-relationships between IGF-1R and AT1R in cardiac fibroblasts.

Canonical TGF $\beta$ signaling occurs via phosphorylation of Smad2 and Smad3. Notably, cardiac fibroblast-specific deletion of Smad3 but not Smad2 significantly attenuates the cardiac fibrotic response to pressure overload [34]. Our study is the first to investigate the activation of Smad3 in fibroblasts in the context of Angll stimulation. Consequently, IGF-1 alleviates Angll-mediated cardiac fibrosis via its ability to inhibit Smad3 phosphorylation. Additionally, Akt phosphorylation is required for IGF-1 action to inhibit aSMA expression. Although TGF $\beta$ is known to induce a non-canonical response via the PI3K/Akt, RhoA-ROCK, and MAPK cascades during differentiation of cardiac fibroblasts [35], no changes in Akt phosphorylation were found in Angll/PE-infused mouse hearts or Angll-treated cardiac fibroblasts in this study. Further studies are needed to fully elucidate the profibrotic pathways mediated by TGF $\beta$ or Angll.

In conclusion, our findings demonstrate that IGF-1 is a critical regulator of cardiac fibrosis and could be a potential therapeutic agent for the management of Angll-associated cardiac fibrosis.

\section{Limitations of the study}

This study had several limitations. First, although we clearly demonstrated that IGF-1 attenuated cardiac fibrosis in an Angllinfusion mouse model, cardiac fibrosis is already present in pathological conditions, such as hypertension or myocardial infarction, when antifibrotic treatment is started in humans. Thus, future studies should address whether IGF-1 treatment significantly reverses established cardiac fibrosis in complementary models. Second, we did not measure blood IGF-1 concentrations or systolic blood pressure in CIGF1RKO mice in the current study.

\section{MATERIALS AND METHODS \\ Mouse models}

A tamoxifen-inducible myofibroblast-specific IGF-1R KO (CFIGF1RKO: IGF$1 \mathrm{R}^{\mathrm{f} / \mathrm{f} / \mathrm{Postn}} \mathrm{MCM}^{\mathrm{M}}$ ) mouse model was generated by crossing mice homozygous for floxed IGF-1R alleles in which loxP sites flank exon 3 of the IGF$1 \mathrm{R}$ gene [6] with mice containing a tamoxifen-inducible Cre recombinase (MerCreMer) expression cassette within the Postn genetic locus (PostnMCM) [36]. The PostnMCM knock-in mice were obtained from Dr. Jeffery Molkentin (Cincinnati Children's Hospital Medical Center, USA). All mice were maintained on a C57BL6J background. Tamoxifen was dissolved in corn oil at a final concentration of $4 \mathrm{mg} / \mathrm{mL}$ and injected intraperitoneally into mice for 4 consecutive days at a dose of $40 \mu \mathrm{g} / \mathrm{g}$ BW using a 27-gauge needle. We injected the same amount of tamoxifen to wildtype (WT: IGF- $1 \mathrm{R}^{\mathrm{f} / \mathrm{ff}}$ ) mice to exclude the confounding results from tamoxifeninduced cardiac toxicity [37]. To induce periostin-expressing cardiac myofibroblasts, we used an established Angll/PE-infusion model, as previously described [36]. Periostin is expressed by injury-induced activated cardiac fibroblasts but not expressed in quiescent fibroblasts. Under $1.5 \%$ isoflurane anesthesia, osmotic minipumps were implanted subcutaneously, delivering $1.2 \mu \mathrm{g} / \mathrm{g} /$ day Angll (Sigma, St. Louis, MO, USA; cat. no. A9525; $50 \mathrm{mg}$ ) and $35 \mu \mathrm{g} / \mathrm{g} /$ day PE HCl (Sigma; cat. no. P6126-5G) for 7 days. Control animals were infused with saline. Mice were randomly assigned to each infusion group. Random assignment was based on a table generated by PASS ${ }^{\mathrm{TM}} 11$ software (NCSS, Kaysville, UT, USA). The randomization code was generated by a statistician who was not otherwise involved in the study. Exclusion criteria of experimental mice were infection after minipump implantation. In the second experiment, male C57BL6 mice (8-10 weeks of age) were randomly assigned to the four osmotic minipump infusion groups: (1) vehicle infusion, (2) Angll infusion, (3) IGF-1 infusion, and (4) Angll plus IGF-1 infusion. The mice were treated for 7 days before harvesting hearts. The animals were fed standard chow and housed in temperature-controlled, pathogen-free facilities with a $12 \mathrm{~h}$ light/dark cycle. No blinding was used. In vivo experiments included at least three mice per group. The sample sizes are sufficient to determine whether there is a meaningful difference among experimental groups according to previous studies performed by our laboratory. All animal experiments were conducted following guidelines approved by the Institutional Animal Care and Use Committee of Chung-Ang University; the investigation conforms with the Guide for the Care and Use of Laboratory Animals published by the US National Institutes of Health. The mice were not subjected to any invasive or metabolic studies other than echocardiography.

\section{Echocardiography}

Mice were anesthetized with isoflurane via inhalation (3\% for induction and $1.5 \%$ for maintenance of anesthesia) using a laboratory animal anesthesia machine (VetEquip, Vivermore, CA, USA). Echocardiography was performed using the Vevo 770 System (VisualSonics Inc., Toronto, Ontario, Canada) with a $30-\mathrm{MHz}$ transducer in the 2-dimensional and $\mathrm{M}$-mode images.

\section{Blood pressure measurements}

Noninvasive systolic blood pressure was measured by tail-cuff methodology using the BP-2000 Blood Pressure Analysis System (Visitech Systems). The occlusion cuff was placed at the base of the tail and the volume-pressure recording sensor cuff was placed adjacent to the occlusion cuff. Mice were trained for 2 days, then consecutive measurements of 15-20 times were recorded. The average of the measured values over 3 days was used in the analysis [38].

\section{Isolation of cardiomyocytes and fibroblasts from adult mice or} rats

Mice or rats were euthanized by inhalation of 3-5\% isoflurane. Cardiomyocytes and cardiac fibroblasts were isolated using retrograde Langendorff perfusion, as previously described [39]. Fifteen-gauge (rats) and 20-gauge (mice) needles were inserted into the aorta, and the hearts were immediately perfused with an EDTA buffer for $5 \mathrm{~min}$ and perfusion buffer for $5 \mathrm{~min}$. Subsequently, the hearts were perfused with enzyme solution (collagenase type II [Worthington; cat. no. LS004176]; $1.2 \mathrm{mg} / \mathrm{mL}$ / protease [Sigma; cat. no. P5147; $0.08 \mathrm{mg} / \mathrm{mL}$ ) for $45 \mathrm{~min}$ (rats) or $10 \mathrm{~min}$ (mice) and then separated. The enzyme solution was neutralized using a $2 \%$ fetal bovine serum stop solution, and the cell suspension was filtered through a $100 \mu \mathrm{m}$ cell strainer. The filtered cell suspension was collected and centrifuged at $300 \times g$ for $10 \mathrm{~min}$. After centrifugation, the supernatant (noncardiomyocyte fraction) was collected for incubation of fibroblasts, and the cell pellet was resuspended in calcium reintroduction buffer for incubation of cardiomyocytes. Isolated cardiomyocytes were plated in laminin-coated dishes and allowed to attach for $3 \mathrm{~h}$, and the growth medium was then added. For cultures of adult rat cardiac fibroblasts, noncardiomyocyte fractions were added and incubated in a growth medium, with medium changes every $2-3$ days in $100 \mathrm{~mm}$ dishes to eliminate cellular debris and endothelial cells. Cardiac fibroblasts were then seeded in 35 or $60 \mathrm{~mm}$ dishes. For cultures of adult mice cardiac fibroblasts, noncardiomyocyte fractions were seeded in $60 \mathrm{~mm}$ dishes, the medium was changed after 1 day, and cells were then cultured for $72 \mathrm{~h}$ for collection of culture medium for IGF-1 ELISA analysis and immunocytochemistry. The collected culture medium was centrifuged at 13,000 rpm for 10 min at $4^{\circ} \mathrm{C}$, and supernatants were used for IGF-1 ELISA (cat. no. MG100; R\&D Systems, USA). All in vitro experiments were performed at least three times.

\section{Histological analysis}

Following deep anesthesia with $3 \%$ isoflurane, the mice were sacrificed by cervical dislocation. The tissue preparation and staining were performed as described previously [40-42]. Cardiomyocytes and cardiac fibroblasts from adult mice or cardiac fibroblasts from adult rats were seeded into culture plates with coverslips. Cells were fixed with $20 \% \mathrm{MeOH}$ for $15 \mathrm{~min}$ at $-20^{\circ} \mathrm{C}$. Cells were then permeabilized for $10 \mathrm{~min}$ with $0.1 \%$ Tween- 20 in phosphate-buffered saline (PBS) and blocked with $10 \%$ bovine serum albumin (BSA) blocking solution in PBS for $1 \mathrm{~h}$ at room temperature. Cells were incubated with primary antibodies (anti-IGF1R [Santa Cruz Biotechnology, Dallas, TX, USA; cat. no. sc-713; dilution, 1:50]; anti-aSMA [SigmaAldrich; cat. no. A5288; dilution, 1:100]) overnight at $4^{\circ} \mathrm{C}$. The next day, cells were washed three times for $10 \mathrm{~min}$ each and then incubated with fluorescent-labeled secondary antibodies (Alexa Fluor goat anti-rabbit or anti-mouse $\operatorname{lgG}$ ) for $1 \mathrm{~h}$ at room temperature. Cells were washed for $10 \mathrm{~min}$ in PBS, and coverslips were mounted with DAPI solution. Images were obtained using a confocal microscope (LSM 700; Carl Zeiss). For histological analysis of mouse heart tissues, heart tissues were fixed in $4 \%$ paraformaldehyde, incubated in $15-30 \%$ sucrose overnight at $4{ }^{\circ} \mathrm{C}$, and mounted in OCT compound at -20 to $-80^{\circ} \mathrm{C}$. Frozen sections $(6 \mu \mathrm{m})$ were 
washed in TDW for removal of the OCT compound. Sirius Red staining was performed by incubation in Bouin's solution for $1 \mathrm{~h}$ at $65^{\circ} \mathrm{C}$ and $0.1 \%$ Sirius Red solution for $1 \mathrm{~h}$ at room temperature. For immunohistochemical analysis of $\mathrm{Ki} 67$ and aSMA, peroxidase activity was blocked with $3 \% \mathrm{H}_{2} \mathrm{O}_{2}$ in $\mathrm{MeOH}$ for 20 min at room temperature. Slides were then incubated with blocking solution (5\% BSA) for $1 \mathrm{~h}$ and treated with primary antibodies (anti-Ki67 [Abcam, Cambridge, UK; cat. no. ab16667; dilution, 1:50]; antiaSMA [Cell Signaling Technology, Danvers, MA, USA; cat. no. 19245; dilution, 1:50]) for $45 \mathrm{~min}$ at $37^{\circ} \mathrm{C}$. In addition, samples were incubated with biotinylated secondary antibodies and avidin-biotin complex reagents (Vector Laboratories; cat. no. PK6100) for $30 \mathrm{~min}$ at room temperature. Chromogenic detection was performed using a DAB Substrate Kit. For immunofluorescence analysis of IGF-1R, aSMA, and Ki67, slides were permeabilizated with $0.3 \%$ PBS-T for $15 \mathrm{~min}$ at room temperature and then incubated with $10 \%$ BSA for $1 \mathrm{~h}$ and primary antibodies (anti-IGF-1R [Santa Cruz Biotechnology; cat. no. sc-713; dilution, 1:50]; anti-aSMA [Cell Signaling Technology; cat. no. 19245; dilution, 1:200]; anti-Ki67 [eBioscience; cat. no. 14-5698-82; dilution, 1:50]) overnight at $4{ }^{\circ} \mathrm{C}$. Samples were then labeled with Cy3-conjugated anti-aSMA [Sigma-Aldrich; cat. no. C6198; dilution, 1:200] antibody, goat anti-rabbit IgG (H+L)-Alexa Fluor 488, and goat anti-rat IgG $(\mathrm{H}+\mathrm{L})$-Alexa Fluor 568. Slides were washed for 15 min in PBS, and coverslips were mounted with DAPI solution. Images were obtained using a confocal microscope (LSM 700; Carl Zeiss). The number of positively stained cells was calculated in each of six mice per group using Image J software.

\section{Western blot analysis}

Heart tissues or cells from mice were lysed with lysis buffer $(20 \mathrm{mM}$ Tris- $\mathrm{HCl}, \mathrm{pH}$ 7.4; $1 \%$ Triton X-100; $1 \mathrm{mM}$ EDTA; $30 \mathrm{mM}$ HEPES; $50 \mathrm{mM}$ $\mathrm{Na}_{4} \mathrm{P}_{2} \mathrm{O}_{7} ; 100 \mathrm{mM} \mathrm{NaF}$ ) containing $1 \times$ Protease Inhibitor Cocktail (Roche Molecular Biochemicals, Indianapolis, IN, USA) and phosphatase inhibitors. Lysates were incubated on ice for $15 \mathrm{~min}$ and centrifuged at 13,000 rpm at $4{ }^{\circ} \mathrm{C}$ for $10 \mathrm{~min}$. The supernatants were used for western blot analysis. Protein quantification was performed using BCA assays, and proteins were separated by sodium dodecyl sulfate-polyacrylamide gel electrophoresis on $8-10 \%$ gels. Proteins were transferred to polyvinylidene difluoride membranes and blocked. Primary antibodies were diluted in blocking solution (5\% BSA in TBST) according to the manufacturer's protocol (antiIGF-1R [Santa Cruz Biotechnology; cat. no. sc-713; dilution, 1:500]; phospho-SMAD3 [Abcam; cat. no. ab52903; dilution, 1:1500]; anti-SMAD3 [Sigma-Aldrich; cat. no. ZRB1005; dilution, 1:1000 for mouse samples]; phospho-SMAD2 [Cell Signaling Technology; cat. no. 3108; dilution, 1:1000]; anti-SMAD2/3 [Cell Signaling Technology; cat. no. 8685; dilution, 1:1000]; anti-phospho-ERK [Cell Signaling Technology; cat. no. 9101; dilution, 1:2000]; anti-ERK [Cell Signaling Technology; cat. no. 9102; dilution, 1:2000]; anti-phospho-mammalian target of rapamycin [mTOR; Cell Signaling Technology; cat. no. 2974; dilution, 1:1000]; anti-mTOR [Cell Signaling Technology; cat. no. 2972; dilution, 1:1000]; anti-phospho-AKT [Cell Signaling Technology; cat. no. 4060; dilution, 1:1000]; anti-AKT [Cell Signaling Technology; cat. no. 9272; dilution, 1:1000]; anti-aSMA [Cell Signaling Technology; cat. no. 19245; dilution, 1:2000]; anti-ROCK1 [Cell Signaling Technology; cat. no. 4035; dilution, 1:1000]; anti-ROCK2 [Cell Signaling Technology; cat. no. 9029; dilution, 1:1000]; and antiglyceraldehyde 3-phosphate dehydrogenase [Cell Signaling Technology; cat. no. 2118; dilution, 1:2000]). Membranes were then incubated with secondary antibodies in 5\% skim milk for $1 \mathrm{~h}$ at room temperature, and protein bands were visualized using EzWestLumi ECL solution. Densitometric quantification was performed using Bio-Rad Image Lab software (Bio-Rad Laboratories, Hercules, CA, USA).

\section{RNA isolation and semi-quantitative or quantitative RT-PCR analysis}

Total RNA was obtained from the heart tissues or cells using the RiboEx Total RNA Solution. First-strand cDNA was synthesized from $1 \mu \mathrm{g}$ total RNA with random primers using a $20 \mu \mathrm{L}$ reverse transcription system (Thermo Scientific; cat. no. K1622). The CDNA was then used for semiquantitative or quantitative RT-PCR. PCR was performed using EmeraldAmp PCR Master Mix (TaKaRa, Shiga, Japan) for semiquantitative RT-PCR and SsoFast EvaGreen Supermix (Bio-Rad LAboratories) for quantitative PCR. Semiquantitative RT-PCR condition was as follows: $94^{\circ} \mathrm{C}$ for $5 \mathrm{~min}$ followed by 27 cycles at $94^{\circ} \mathrm{C}$ for $30 \mathrm{~s}, 60^{\circ} \mathrm{C}$ for $30 \mathrm{~s}, 72^{\circ} \mathrm{C}$ for $45 \mathrm{~s}$, and a final extension at $72{ }^{\circ} \mathrm{C}$ for $7 \mathrm{~min}$. The quantitative RT-PCR condition was as follows: $95^{\circ} \mathrm{C}$ for 2 min followed by 35 cycles at $95^{\circ} \mathrm{C}$ for $10 \mathrm{~s}, 56^{\circ} \mathrm{C}$ for $10 \mathrm{~s}, 72^{\circ} \mathrm{C}$ for $15 \mathrm{~s}$, and then melting curves were analyzed. The 185 rRNA was used as a normalization gene. Primers are listed in Table S3. To assess the specificity of the amplified PCR products, a post-amplification melting curve analysis was performed, and relative quantification was calculated using the comparative cycle threshold method.

\section{Statistical analysis}

Data are presented as the mean \pm SEM. For intergroup comparisons, the distribution of the data was firstly evaluated for normality using the Shapiro-Wilk test, Shapiro-Wilk test after log-transformation, and q-q plot The normally distributed data were compared using a $t$-test or two-way ANOVA. Non-normally distributed data were analyzed using either a Mann-Whitney U-test or Mann-Whitney U-test with adjusting the a-level by Bonferroni inequality. For serial data, within-group difference was analyzed with the linear mixed-effects model (LMEM). Levene's test for homogeneity of variances was performed. $P<0.05$ was considered statistically significant. All analyses were conducted using the Statistical Package for the Social Sciences software suite (version 23; IBM Corp., Armonk, NY, USA).

\section{REFERENCES}

1. Travers JG, Kamal FA, Robbins J, Yutzey KE, Blaxall BC. Cardiac fibrosis: the fibroblast awakens. Circ Res. 2016;118:1021-40.

2. Díez J, González A, Kovacic JC. Myocardial interstitial fibrosis in nonischemic heart disease, Part 3/4: JACC focus seminar. J Am Coll Cardiol. 2020;75:2204-18.

3. Gibb AA, Lazaropoulos MP, Elrod JW. Myofibroblasts and fibrosis: mitochondrial and metabolic control of cellular differentiation. Circ Res. 2020;127:427-47.

4. Parichatikanond W, Luangmonkong T, Mangmool S, Kurose H. Therapeutic targets for the treatment of cardiac fibrosis and cancer: focusing on TGF- $\beta$ signaling. Front Cardiovasc Med. 2020;7:34.

5. Troncoso R, Ibarra C, Vicencio JM, Jaimovich E, Lavandero S. New insights into IGF-1 signaling in the heart. Trends Endocrinol Metab. 2014;25:128-37.

6. Kim J, Wende AR, Sena S, Theobald HA, Soto J, Sloan C, et al. Insulin-like growth factor I receptor signaling is required for exercise-induced cardiac hypertrophy. Mol Endocrinol. 2008;22:2531-43.

7. Ock S, Lee WS, Ahn J, Kim HM, Kang H, Kim HS, et al. Deletion of IGF-1 receptors in cardiomyocytes attenuates cardiac aging in male mice. Endocrinology. 2016;157:336-45

8. Huynh K, McMullen JR, Julius TL, Tan JW, Love JE, Cemerlang N, et al. Cardiacspecific IGF-1 receptor transgenic expression protects against cardiac fibrosis and diastolic dysfunction in a mouse model of diabetic cardiomyopathy. Diabetes. 2010;59:1512-20.

9. Báez-Díaz C, Blanco-Blázquez V, Sánchez-Margallo FM, Bayes-Genis A, González I, Abad A, et al. Microencapsulated Insulin-Like Growth Factor-1 therapy improves cardiac function and reduces fibrosis in a porcine acute myocardial infarction model. Sci Rep. 2020;10:7166.

10. Shimizu T, Narang $N$, Chen $P, Y u$ B, Knapp $M$, Janardanan J. et al. Fibroblast deletion of ROCK2 attenuates cardiac hypertrophy, fibrosis, and diastolic dysfunction. JCI Insight. 2017;2:e93187.

11. Takeda N, Manabe I, Uchino Y, Eguchi K, Matsumoto S, Nishimura S, et al. Cardiac fibroblasts are essential for the adaptive response of the murine heart to pressure overload. J Clin Investig. 2010;120:254-65.

12. Khan SA, Dong H, Joyce J, Sasaki T, Chu ML, Tsuda T. Fibulin-2 is essential for angiotensin II-induced myocardial fibrosis mediated by transforming growth factor (TGF)- $\beta$. Lab Investig. 2016;96:773-83.

13. Zhu Y, Gu J, Zhu T, Jin C, Hu X, Wang X. Crosstalk between Smad2/3 and specific isoforms of ERK in TGF- $\beta 1$-induced TIMP-3 expression in rat chondrocytes. J Cell Mol Med. 2017;21:1781-90.

14. Hayashida T, Decaestecker M, Schnaper HW. Cross-talk between ERK MAP kinase and Smad signaling pathways enhances TGF-beta-dependent responses in human mesangial cells. FASEB J. 2003;17:1576-8.

15. Molkentin JD, Bugg D, Ghearing N, Dorn LE, Kim P, Sargent MA, et al. Fibroblastspecific genetic manipulation of p38 mitogen-activated protein kinase in vivo reveals its central regulatory role in fibrosis. Circulation. 2017;136:549-61.

16. Gao X, He X, Luo B, Peng L, Lin J, Zuo Z. Angiotensin II increases collagen I expression via transforming growth factor-beta1 and extracellular signalregulated kinase in cardiac fibroblasts. Eur J Pharm. 2009;606:115-20.

17. Brilla CG, Funck RC, Rupp H. Lisinopril-mediated regression of myocardial fibrosis in patients with hypertensive heart disease. Circulation. 2000;102:1388-93.

18. Díez J, Querejeta R, López B, González A, Larman M, Martínez Ubago JL. Losartandependent regression of myocardial fibrosis is associated with reduction of left ventricular chamber stiffness in hypertensive patients. Circulation. 2002;105:2512-7.

19. Lewis GA, Schelbert EB, Naish JH, Bedson E, Dodd S, Eccleson H, et al. Pirfenidone in heart failure with preserved ejection fraction-rationale and design of the PIROUETTE Trial. Cardiovasc Drugs Ther. 2019;33:461-70. 
20. Aimo A, Cerbai E, Bartolucci G, Adamo L, Barison A, Lo Surdo G, et al. Pirfenidone is a cardioprotective drug: mechanisms of action and preclinical evidence. Pharm Res. 2020;155:104694.

21. Campbell SE, Katwa LC. Angiotensin II stimulated expression of transforming growth factor-beta1 in cardiac fibroblasts and myofibroblasts. J Mol Cell Cardiol. 1997;29:1947-58.

22. Carvajal G, Rodríguez-Vita J, Rodrigues-Díez R, Sánchez-López E, Rupérez $M$, Cartier C, et al. Angiotensin II activates the Smad pathway during epithelial mesenchymal transdifferentiation. Kidney Int. 2008;74:585-95.

23. White SJ, Chong JJH. Growth factor therapy for cardiac repair: an overview of recent advances and future directions. Biophys Rev. 2020;12:805-15.

24. O'Sullivan JF, Leblond AL, Kelly G, Kumar AH, Metharom P, Büneker CK, et al. Potent long-term cardioprotective effects of single low-dose insulin-like growth factor-1 treatment postmyocardial infarction. Circ Cardiovasc Int. 2011;4:327-35.

25. Lai NC, Tang T, Gao MH, Saito M, Miyanohara A, Hammond HK. Improved function of the failing rat heart by regulated expression of insulin-like growth factor I via intramuscular gene transfer. Hum Gene Ther. 2012;23:255-61.

26. Castellano G, Affuso F, Conza PD, Fazio S. The GH/IGF-1 axis and heart failure. Curr Cardiol Rev. 2009;5:203-15.

27. Heinen A, Nederlof R, Panjwani P, Spychala A, Tschaidse T, Reffelt H, et al. IGF1 treatment improves cardiac remodeling after infarction by targeting myeloid cells. Mol Ther. 2019;27:46-58.

28. Nishizawa H, Iguchi G, Fukuoka H, Takahashi M, Suda K, Bando H, et al. IGF-I induces senescence of hepatic stellate cells and limits fibrosis in a p53dependent manner. Sci Rep. 2016;6:34605.

29. Wu Z, Yu Y, Niu L, Fei A, Pan S. IGF-1 protects tubular epithelial cells during injury via activation of ERK/MAPK signaling pathway. Sci Rep. 2016;6:28066.

30. Shimizu T, Liao JK. Rho kinases and cardiac remodeling. Circ J. 2016;80:1491-8.

31. Yang X, Li Q, Lin X, Ma Y, Yue X, Tao Z, et al. Mechanism of fibrotic cardiomyopathy in mice expressing truncated Rho-associated coiled-coil protein kinase 1. FASEB J. 2012;26:2105-16.

32. Sunamura S, Satoh K, Kurosawa R, Ohtsuki T, Kikuchi N, Elias-Al-Mamun M, et al. Different roles of myocardial ROCK1 and ROCK2 in cardiac dysfunction and postcapillary pulmonary hypertension in mice. Proc Natl Acad Sci USA. 2018;115: E7129-e7138.

33. Jia G, Aggarwal A, Yohannes A, Gangahar DM, Agrawal DK. Cross-talk between angiotensin II and IGF-1-induced connexin 43 expression in human saphenous vein smooth muscle cells. J Cell Mol Med. 2011;15:1695-702.

34. Khalil H, Kanisicak O, Prasad V, Correll RN, Fu X, Schips T, et al. Fibroblast-specific TGF- $\beta$-Smad2/3 signaling underlies cardiac fibrosis. J Clin Investig. 2017;127:3770-83.

35. Yousefi F, Shabaninejad Z, Vakili S, Derakhshan M, Movahedpour A, Dabiri H, et al. TGF- $\beta$ and WNT signaling pathways in cardiac fibrosis: non-coding RNAs come into focus. Cell Commun Signal 2020;18:87.

36. Kanisicak O, Khalil H, Ivey MJ, Karch J, Maliken BD, Correll RN, et al. Genetic lineage tracing defines myofibroblast origin and function in the injured heart. Nat Commun. 2016;7:12260.

37. Bersell K, Choudhury S, Mollova M, Polizzotti BD, Ganapathy B, Walsh S, et al. Moderate and high amounts of tamoxifen in aMHC-MerCreMer mice induce a DNA damage response, leading to heart failure and death. Dis Model Mech. 2013;6:1459-69.

38. Wang YY, Jiang H, Pan J, Huang XR, Wang YC, Huang HF, et al. Macrophage-tomyofibroblast transition contributes to interstitial fibrosis in chronic renal allograft injury. J Am Soc Nephrol. 2017;28:2053-67.

39. Meszaros JG, Gonzalez AM, Endo-Mochizuki Y, Villegas S, Villarreal F, Brunton LL. Identification of $G$ protein-coupled signaling pathways in cardiac fibroblasts: cross talk between G(q) and G(s). Am J Physiol Cell Physiol. 2000;278:C154-162.

40. Ock S, Ahn J, Lee SH, Park H, Son JW, Oh JG, et al. Receptor activator of nuclear factor-kappaB ligand is a novel inducer of myocardial inflammation. Cardiovasc Res. 2012;94:105-14.

41. Satoh M, Ogita H, Takeshita K, Mukai Y, Kwiatkowski DJ, Liao JK. Requirement of Rac1 in the development of cardiac hypertrophy. Proc Natl Acad Sci USA. 2006;103:7432-7.
42. Sun XL, Chen BY, Zhao HK, Cheng YY, Zheng MH, Duan L, et al. Gas1 upregulation is inducible and contributes to cell apoptosis in reactive astrocytes in the substantia nigra of LPS and MPTP models. J Neuroinflamm. 2016;13:180.

\section{ACKNOWLEDGEMENTS}

We thank Dr. Martin Holzenberger for the IGF- $1 R^{f / f l}$ mouse line.

\section{AUTHOR CONTRIBUTIONS}

Conception and design: WSL and JK. Acquisition of data: SO, WH, CWK. Interpretation of data: SO, WH, CWK, HK, WSL, and JK. Statistical analysis: HK. Writing and review of the manuscript: SO, WSL, and JK. Study supervision: WSL and JK.

\section{FUNDING}

This work was supported by grants of the Basic Science Research Program through the National Research Foundation of Korea (2018R1D1A1B07046712 to SO, 2020R1A2C1009647 to WSL and 2020R1A2C1010217 to JK).

\section{ETHICS STATEMENT}

All animal experiments were conducted following guidelines approved by the Institutional Animal Care and Use Committee of Chung-Ang University; the investigation conforms with the Guide for the Care and Use of Laboratory Animals published by the US National Institutes of Health.

\section{COMPETING INTERESTS}

The authors declare no competing interests.

\section{ADDITIONAL INFORMATION}

Supplementary information The online version contains supplementary material available at https://doi.org/10.1038/s41419-021-03965-5.

Correspondence and requests for materials should be addressed to W.S.L. or J.K.

Reprints and permission information is available at http://www.nature.com/ reprints

Publisher's note Springer Nature remains neutral with regard to jurisdictional claims in published maps and institutional affiliations.

Open Access This article is licensed under a Creative Commons Attribution 4.0 International License, which permits use, sharing, adaptation, distribution and reproduction in any medium or format, as long as you give appropriate credit to the original author(s) and the source, provide a link to the Creative Commons license, and indicate if changes were made. The images or other third party material in this article are included in the article's Creative Commons license, unless indicated otherwise in a credit line to the material. If material is not included in the article's Creative Commons license and your intended use is not permitted by statutory regulation or exceeds the permitted use, you will need to obtain permission directly from the copyright holder. To view a copy of this license, visit http://creativecommons. org/licenses/by/4.0/.

(c) The Author(s) 2021 